revista do ieb n 45 p. $153-176$ set 2007

\title{
Modernidade tropical: visões norte- americanas da Amazônia nas vésperas da Guerra Fria
}

\section{Barbara Weinstein ${ }^{1}$}

\section{Resumo}

Este artigo estuda duas representações da Amazônia e seu potencial para o desenvolvimento produzidas em 1944 como parte da "Política da Boa Vizinhança", promovida pelos Estados Unidos durante a II Guerra Mundial. Analisa o filme do Estúdio Disney The Amazon awakens ("A Amazônia acorda"), cujo retrato da Amazônia como urbanizada e incipientemente moderna contrasta com a usual atenção dada ao exotismo regional e à alteridade. Ao acentuar o potencial da Amazônia para o progresso, o filme visualiza elementos-chave daquilo que se tornaria conhecido como "teoria da modernização", baseada na noção de que todas as pessoas aspiram a um modo de vida mais moderno, e que só precisam da tecnologia e do capital apropriados para repetir a trajetória das sociedades mais "avançadas”. Em seguida, procedemos a uma comparação do filme com o livro de Earl Parker Hanson sobre a Amazônia como uma "nova fronteira", o qual, ao mesmo tempo em que coincide com aspectos do filme da Disney, diverge do mesmo no que se refere a aspectos importantes, que indicam as ambivalências presentes nas visões norte-americanas da região. Finalmente, o artigo se debruça brevemente sobre o papel da Guerra Fria no que se refere ao atraso da adoção da teoria da modernização como uma crença central das políticas norte-americanas para a América Latina.

\section{Palavras-chave}

Amazônia, Disney, teoria da modernização, fronteira, Fordlândia.

1 Professora do Departamento de História da Universidade de Nova Iorque (NYU). 


\section{Tropical modernity: north american visions of the Amazon on the eve of the Cold War}

Barbara Weinstein

Abstract

This article examines two representations of the Amazon and its potential for development produced in 1944 as part of the "Good Neighbor Policy" promoted by the United States during World War II. It analyzes the Disney film The Amazon awakens, whose portrayal of the Amazon as urbanized and incipiently modern, contrasts with the usual attention to regional exoticism and otherness. In accentuating the Amazon's potential for progress, the film visualizes key elements of what would become known as "modernization theory", based on the notion that all peoples aspire to a more modern way of life, and only need the appropriate technology and capital to replicate the trajectory of more "advanced" societies. This is then compared with a book by Earl Parker Hanson on the Amazon as a "new frontier", which both coincides with aspects of the Disney film and diverges from it in significant ways, indicating the ambivalences in North American visions of the region. Finally, the article briefly considers the role of the Cold War in delaying the adoption of modernization theory as the central tenet of US policies for Latin America.

\section{Keywords}

Amazon, Disney, modernization theory, frontier, Fordlândia. 
Era uma vez uma região tropical, bela e cheia de promessas, um "paraíso de riqueza além dos sonhos dos homens", que atraía o interesse de caçadores de fortuna de todos os cantos da Terra. Mas esta bela região, atolada pelas maldições da história e da cultura, sofria de uma tecnologia arcaica e de insuficiência de capital. Por isso, ficou adormecida, num sono profundo e atemporal. Até o dia em que o Príncipe Charmoso, que por coincidência era a imagem de Henry Ford, conferiu-lhe um beijo, seu abundante capital e extraordinárias inovações tecnológicas; a região finalmente se levantou, despertando para se unir ao Príncipe Charmoso no caminho do progresso.

Este "conto de fadas" pode parecer uma paródia ou uma invenção, mas eu acredito nele - isto é, acredito ser uma narrativa que realmente capta as convenções genéricas e o espírito do filme The Amazon awakens (A Amazônia acorda). Trata-se de um documentário lançado em 1944, resultado de uma co-produção entre o Office of the Coordinator of Inter-American Affairs (Agência do Coordenador de Assuntos Inter-Americanos), chefiado pelo jovem Nelson Rockefeller, e o Estúdio de Walt Disney ${ }^{2}$. Ele fazia parte de um corpus de filmes comerciais e documentários dedicados a promover a chamada Política da Boa Vizinhança na América Latina durante a Segunda Guerra Mundial. Essa coleção cinematográfica incluía exemplares lançados nos cinemas comerciais - por exemplo, os filmes de desenho animado, Os Três cavalheiros e Saludos amigos -, tanto quanto filmes não-ficcionais. Estes abrangiam assuntos tão intrigantes como as "transformações das estruturas agrárias no Chile" e "a versatilidade do feijão de soja”. A platéia para a qual essas obras menos comerciais eram destinadas é um pouco difícil de determinar. Várias delas foram exibidas, com dublagem em espanhol ou em português, ao ar livre a um público latino-americano (este era especialmente o caso dos filmes que tratavam de questões de higiene pública) ${ }^{3}$. Quanto a

2 Meus agradecimentos a Pennee Bender, estudiosa dos filmes da Política da Boa Vizinhança, por ter-me avisado da existência do filme The Amazon Awakens e por haver arrumado uma cópia dele para mim. Agradeço também a Seth Garfield, que chamou a minha atenção para o trabalho de Earl Parker Hanson.

3 Sobre o papel de filmes nas relações Estados Unidos-América Latina, veja FEIN, Seth. Everyday forms of transnational collaboration: US Film Propaganda in Cold War Mexico. In: JOSEPH, Gilbert et al. Close Encounters of Empire. Durham: Duke U. Press, 1998. p. 400-450. 0 trabalho de Fein sobre filmes e relações interamericanas é especialmente notável, por sua crítica da linha de argumento de "imperialismo cultural", exemplificada pelo trabalho de Ariel Dorfman e outros. Diferentemente deles, Fein acentua o intercâmbio entre norte-americanos e mexicanos, e a maneira como os mexicanos apropriaram as técnicas do filme norte-americano para fins e propósitos nacionais. Aliás, no caso da Amazônia, esse argumento tem menos força porque o intercâmbio entre os cineastas de Disney e os representantes locais era mínimo. 
aquelas nitidamente destinadas a um público norte-americano, como The Amazon awakens, é provável que fossem distribuídas em instituições educacionais e associações empresariais, como as câmaras do comércio (além de serem exibidas como "shorts" em cinemas ao lado de filmes mais comerciais). A intenção era incentivar a cooperação hemisférica e promover investimentos do setor privado na América Latina. Quanto à decisão de fazer um documentário especificamente sobre a Amazônia, esta provavelmente refletia, em primeiro lugar, a fascinação persistente entre os norte-americanos pela região, bem como a intensificação do interesse pelo Vale do Amazonas, inspirada pela campanha da borracha durante a Segunda Guerra Mundial.

Há vários aspectos do filme realmente fascinantes para o estudioso da história da Amazônia (especialmente no sentido das "representações" da região) e da história das relações Estados Unidos-América Latina. Porém, o assunto que me proponho a destacar neste artigo é o surpreendente e precoce uso dos conceitos principais da teoria da modernização em sua representação da "realidade" amazônica. Esta teoria é normalmente considerada uma tendência inicialmente acadêmica do pósguerra, especialmente dos anos 1950, tendo sido forjada pelos sociólogos preocupados com questões relativas à modernização no chamado Terceiro Mundo. Apesar de o filme de Disney datar dos anos 1940, os elementos da teoria da modernização manifestam-se claramente em seu retrato da Amazônia - até mesmo a Amazônia - como uma região pronta para o desenvolvimento tão logo os recursos tecnológicos e financeiros se tornassem acessíveis. Mais especificamente, o documentário indica repetidas vezes que a aspiração humana "universal" para o progresso e para uma vida melhor é atributo dos habitantes da Amazônia; sua potencialidade para a modernidade e o progresso é definida como "adormecida," dormente, mas latente e inerente - quer dizer, já presente na sua cultura e até no seu cotidiano. Para despertar e realizar essa potencialidade plenamente, só faltaria o estímulo do capital e da tecnologia estrangeiros.

A insistência na disposição "natural" da população da Amazônia para o progresso distingue a perspectiva desse filme das visões anteriores dos Estados Unidos sobre a Amazônia, surgidas durante o ápice do neo-colonialismo norte-americano, quando havia um espírito imperialista sem constrangimentos (nos anos 1910 e 1920, antes da Política da Boa Vizinhança, iniciada nos anos 1930 sob o governo de Franklin Delano Roosevelt).

Na época anterior à Política da Boa Vizinhança, a expressão que definia o colonialismo (tanto norte-americano quanto europeu) era a "missão civilizadora". As potências imperialistas enfatizavam a necessidade de educar os povos "atra- 
sados" no tocante aos aspectos rudimentares da civilização e da cultura modernas. Somente depois de longa tutela sob o domínio das sociedades mais avançadas, estes povos estariam aptos a participar do mundo civilizado. As atitudes norte-americanas para com os "povos latinos" eram, de certa forma, complicadas pelo fato de as sociedades latino-americanas serem, formalmente, países soberanos, com elites europeizadas, e, então, nesse sentido, "nações modernas". Nem a idéia da África selvagem, nem o discurso orientalista sobre a Ásia e o Oriente Médio, divulgados pelos países imperialistas da Europa, adequavam-se à América Latina.

Portanto, as visões norte-americanas da região tendiam a ser um pastiche, uma mistura de elementos oriundos de fontes como a Lenda Negra da conquista ibérica; o racismo "científico" da época; a idéia dos trópicos como um local de degenerescências; o catolicismo como um impedimento ao progresso etc. 0 efeito era idêntico ao do orientalismo: gerou-se um discurso da "diferença" que postava as populações latino-americanas (e sobretudo, aquelas das regiões como a amazônica) fora do mundo dos povos bem-sucedidos e civilizados, por isso situando-as como necessitadas de uma relação de dependência para com os povos dominantes.

É só levando este discurso anterior em consideração que podemos apreciar a novidade representada por The Amazon awakens. Em vez de destacar a diferença, ou mesmo o exótico da floresta, a obra retrata o povo da região como aspirante a um padrão de vida muito parecido, se não idêntico, com o da classe média norte-americana. Nela, a Amazônia é uma sociedade pronta para decolar ["take off"] e para aproveitar o capital e o know-how oferecidos pelos Estados Unidos. Claro que a Amazônia precisava deste último para acordar plenamente e livrar-se dos remanescentes dos velhos hábitos e atitudes. 0 retrato dos habitantes da região é, no filme, o de um povo bem disposto a receber precisamente essa ajuda.

A segunda preocupação deste artigo é examinar o que estava incluído e o que estava excluído na reconstrução histórica do documentário, naquilo que dizia sobre o passado, o presente e o futuro da Amazônia. Para esse fim, analiso-o em conjunto com outro "texto" - um pequeno trabalho do geógrafo Earl Parker Hanson, intitulado The Amazon: a new frontier? (A Amazônia: uma nova fronteira?) ${ }^{4}$. Ele publicou este livrinho ou en-

4 HANSON, Earl Parker. The Amazon: a new frontier. Nova Iorque: Foreign Policy Association, Mar. 1944. (Headline Series, 45). 
saio, de 90 páginas, em março de 1944, numa série de trabalhos patrocinada pela Foreign Policy Association. Hanson era autor também de outro livro, Journey to Manaos, lançado em 1938, e foi o organizador principal da série New World Guides to the Latin American Republics, publicada pelo Coordinator of InterAmerican Affairs em 1943. Enfim, Earl Parker Hanson estava intimamente associado também ao Office of the Coordinator e publicou o livro sobre a Amazônia no mesmo ano em que aquela entidade, junto com Disney, lançou o filme em questão.

É de se esperar, então, certa coerência na forma de retratar a Amazônia, sua história e sua potencialidade para a modernização, entre o texto de Hanson e o filme de Disney. E eles têm, com efeito, vários pontos em comum, a começar pela visão da Amazônia como uma "fronteira" e a convicção de que a região achava-se pronta para dar um passo gigantesco em direção à modernidade. Entretanto, havia também certas divergências entre ambos, bastante significativas. Tais divergências refletiam, por um lado, os públicos e as convenções distintos de dois gêneros diferentes (filme comercial contra texto quase acadêmico); mas, por outro lado, refletiam a instabilidade e as ambigüidades das idéias sobre a modernização neste momento histórico que antecede a consolidação de um corpus de estudos ligado à chamada "teoria da modernização". Mesmo depois desta consolidação intelectual, a tensão persistiria na teoria entre a ênfase nos processos econômicos, que elevariam um país ao nível das sociedades avançadas, e o pressuposto quase universal em meio a seus adeptos de que os Estados Unidos continuaria como "líder" hemisférico (se não mundial). Esta tensão já se evidencia nessas duas obras, nesses dois textos - o que se torna claro especialmente quando os lemos em conjunto.

Retomando a questão dos silêncios e omissões do filme, um aspecto que imediatamente chama a atenção do espectador do início do século XXI é o silêncio total sobre certos temas - a preservação do meio ambiente, os direitos dos povos indígenas - que hoje seriam fundamentais num filme de produção norte-americana sobre o tema. Ainda mais, havia formas de conhecimento sobre a história e a ecologia da região amplamente acessíveis naquele momento e presentes no livro de Hanson - cuja omissão no filme de Disney torna-se assim gritante. Do meu ponto de vista, estes silêncios e omissões são sistemáticos e servem para avançar e reforçar uma narrativa da história da Amazônia, tanto natural quanto humana, coerente com o discurso da modernização articulado pela narração e pelas imagens do filme.

The Amazon awakens inicia-se com uma seqüência de desenho animado que aproveita um conceito amplamente divulgado no meio norte-americano: a Amazônia como um "El 
Dorado", um reino ainda escondido de riquezas inimagináveis. Sua representação visual no filme é muito parecida com a daquele símbolo também amplamente conhecido do "reino mágico" de Disney, o castelo da Bela Adormecida. Esta seqüência relata, de uma maneira extremamente simplificada e sanitizada, os primeiros anos da conquista e exploração da Amazônia, culminando com uma frase escrita por um dos primeiros viajantes europeus presentes na região, segundo a qual a hiléia amazônica prometia ser "uma nova fronteira para toda humanidade". Aqui podemos notar que a citação original em espanhol, apresentada em um rolo de papel bem ao estilo Disney, era: "a toda la humanidad un nuevo horizonte". A decisão de traduzir "horizonte" como "frontier/fronteira" faz algum sentido em termos lingüísticos, mas a palavra "horizon/horizonte" também serviria perfeitamente. Dado o significado muito forte da palavra "fronteira" na cultura norte-americana, sua escolha não era uma decisão ideologicamente neutra. Embora o narrador se refira ao fato de a Amazônia ser uma região dividida entre "Seis Grandes Nações" (uma lisonja típica da propaganda da Boa Vizinhança), o filme a trata constantemente como um espaço "transnacional" cuja modernização e desenvolvimento poderiam oferecer "comida e casa para inumeráveis milhões de pessoas"(sic).

Neste último sentido, o livro de Hanson encaixa-se bem à obra de Disney, abordando também a Amazônia como um espaço "transnacional". Todavia, há uma série de divergências entre a óptica de Disney e a de Hanson. Uma das preocupações principais deste refere-se ao potencial da Amazônia como local de colonização para refugiados da guerra na Europa e até para norte-americanos. Aliás, ele vai mais longe, citando a experiência de Queensland na Austrália como lição-mestra para todas as fronteiras do mundo. Conforme Hanson narra a experiência australiana, inicialmente uma pequena oligarquia de brancos contratava mão-de-obra da Ásia e da África para trabalhar nas grandes fazendas de Queensland, os trabalhadores constituindo uma população oprimida e essencialmente colonial. Percebendo o perigo desse padrão de exploração, o governo australiano expulsou os asiáticos e africanos e resolveu povoar a região, com famílias de brancos que trabalhavam em pequenas e médias lavouras. Formou-se assim um modelo de povoamento que Hanson reputava moderno e oposto ao do colonialismo. Torna-se claro nessa exposição que, segundo o geógrafo, a criação de uma economia baseada na classe média exigiria, num primeiro instante, um povo branco, de ascendência européia. Já o filme de Disney - coerente com seu discurso universalizante - nunca toca explicitamente na questão das diferenças raciais ou étnicas e nem mesmo especifica a composição racial da população ama- 
zônica. A questão racial subordina-se no filme à representação do padrão de vida moderno e urbano, e a presença visual do estrangeiro limita-se à fração dos funcionários da Fordlândia.

Outra divergência diz respeito ao uso da expressão " $E l$ Dorado". Para o filme de Disney, que pretende "seduzir" o empresário norte-americano com capital para investir, ao tema da Amazônia como um "El Dorado" moderno seria impossível resistir. Ao passo que, para Hanson, essa noção de "El Dorado" representava o grande empecilho ao desenvolvimento da fronteira tropical, o pecado original do antigo colonialismo. Ele denuncia essa "psicologia [do El Dorado], que empurra o homem a buscar riquezas silvestres na floresta em vez de se enraizar e desenvolver a terra, dela produzindo uma riqueza sob condições controladas." ${ }^{5}$ Para Hanson a essência do colonialismo (no mau sentido da palavra) residia justamente nesta busca da riqueza fácil e rápida. Seguindo as lições de Queensland, sua receita para desenvolver a Amazônia baseia-se nas colônias de brancos utilizando seus próprios braços para explorar a longo prazo aquelas "riquezas". Ele até insiste em que tal esforço físico acabaria protegendo os brancos dos efeitos degenerativos das doenças tropicais.

Voltando ao filme, as seqüências seguintes, como é totalmente previsível, mostram as grandezas da natureza amazônica. Antes de mais nada, para qualquer filme sobre a Amazônia feito nos Estados Unidos, esse tipo de seqüência seria absolutamente indispensável. As primeiras cenas não animadas oferecem um panorama da formação aquática da Hiléia Amazônica desde a região andina até o Atlântico, exibindo também a flora e a fauna exóticas da região. Esta parte do filme reproduz os cenários clássicos de um paraíso primordial veiculados pela revista $\mathrm{Na}$ tional Geographic, com uma interessante particularidade: o povo indígena, a cultura "primitiva", sempre utilizados na revista para aumentar o exotismo do local, estão totalmente ausentes.

A omissão é previsível porque o filme pretende, de um lado, destacar a exuberância e abundância da natureza da Amazônia, mas, por outro lado, insiste na modernidade incipiente dos habitantes da região. Como patenteia-se ainda mais quando o foco se transfere do Alto para o Baixo Amazonas, esta certamente não é a Amazônia de Tristes Tropiques, de Lévi Strauss; o objetivo não é salientar a diferença ou a "alteridade" da população. Ao contrário, numa manobra de orientalismo ao revés (ou, para citar a palavra do antropólogo Fernando Coronil, de "ocidentalismo"), o filme procura mostrar que os habitantes da Amazônia são exatamente como "nós”, (isto é, como

5 HANSON, Earl Parker. The Amazon: a new frontier. Nova Iorque: Foreign Policy Association, Mar. 1944. p. 37. 
o norte-americano padrão da classe média), tendo as mesmas inclinações, disposições e aspirações ${ }^{6}$. Neste projeto não existe lugar para o espetáculo do homem indígena e "primitivo", aquela figura semi-nua, com seus lábios e orelhas estendidas e a cabeça enfeitada de penas.

Mais uma vez, o contraste com o livrinho de Hanson é impressionante. Longe de excluir os povos indígenas da sua análise, ele lhes dedica um capítulo de oito páginas ${ }^{7}$. Admite que os indios, inevitavelmente, entrarão em declínio caso seja implantado um programa de colonização em grande escala. Porém, considera o índio um exemplo para o colono branco, especialmente no que concerne à dieta e ao trabalho braçal. Hanson propõe uma visão mais "moderna" dos índios: caracteriza-os como "um povo fino e enérgico que tem dominado seu meio-ambiente e por isso tem muito a ensinar aos homens brancos sobre a vida [na Amazônia]". Ele vai mais longe ainda, concordando com aqueles que, citando “as importantes e numerosas contribuições (feitas pelos índios) a nossa própria cultura técnica, dizem que [eles] merecem ser colocados entre os grandes cientistas do mundo inteiro."

Nada deixa mais claras as divergências entre a visão de Disney e a de Hanson do que essa ausência/presença dos povos indígenas. Para Disney importava demonstrar a modernidade incipiente da população, e não havia técnica visual em seu repertório que facultasse a representação do homem indigena como uma figura moderna. Em decorrência, ele tinha que sumir da paisagem, enquanto para Hanson o índio podia servir como guia e colaborador dos futuros colonos, um intermediário entre a natureza amazônica e as técnicas do mundo "avançado".

Voltando ao filme, o narrador reconhece, com um toque bem Disney, que o norte-americano típico pensava na Amazônia como uma floresta imensa e deserta. Assim, depois da excursão pela flora e a fauna, ele declara: "Há gente aqui também!", e o cenário muda repentinamente para a cidade de Iquitos, o primeiro dos três centros urbanos perfilados no filme. Mais uma vez, o cineasta não resiste a inserir um toque do pitoresco e

6 CORONIL, Fernando. Them magical state: nature, money, and modernity in Venezuela. Chicago: Univ. of Chicago Press, 1997.

7 HANSON, Earl Parker. The Amazon: a new frontier. Nova Iorque: Foreign Policy Association, Mar. 1944. p. 51-58.

8 HANSON, Earl Parker. The Amazon: a new frontier. Nova Iorque: Foreign Policy Association, Mar. 1944. p. 53-55. É interessante notar que Hanson, nesse capítulo, discorda vigorosamente do retrato do índio extremamente pejorativo no muito citado livro de FRANK, Waldo. South American Journey. Nova Iorque: Duell, Sloan and Pearce, 1943. p. 302. 
do exótico (um macaquinho mexendo com a máquina fotográfica), mas a missão principal - mostrar a Amazônia como nada diferente de qualquer sociedade em pleno processo de modernização - se manifesta logo. Por exemplo, há cenas da cidade que destacam filas de alunas em uniformes, mulheres bonitas com roupas da moda, praças, prédios e hospitais bem modernos, não faltando referências ao "smart set" - a "turma sofisticada" - local. Enfim, a vida cotidiana de Iquitos, malgrado alguns toques de exotismo, é tratada como pouco diferente da rotina diária da classe média duma cidadezinha típica norte-americana. Nessa versão de Iquitos, não há pobreza nem decadência.

Ademais, uma cena situada nos arredores da cidade, que poderia ter sido emblemática da pobreza e do "atraso" da região, marcada pelo trabalho de mulheres e menores e pela ausência do homem chefe-de-família, é, pelo contrário, construída como um microcosmo/semente da iniciativa empresarial capitalista. 0 cenário é uma pequena "fábrica de botões" onde uma mulher produz, com seu filho pré-adolescente, milhares de botões feitos de um material regional, enquanto balança um nenê pequeno demais para trabalhar, com uma outra criança esperando sua vez na balança improvisada. Em vez de acentuar a dureza ou a monotonia desta vida numa fábrica em miniatura, ou a exploração do menor, ou ainda a negligência das outras crianças, o que está claramente enfatizado na narração é a esperteza do processo de trabalho, e a exaltação desta empresa como precursora da produção moderna em massa, a despeito de operar sob circunstâncias constrangedoras. Aliás, o espectador é incentivado a imaginar como seria maravilhoso esse negócio, se a tenacidade e habilidade nele observadas fossem casadas com o capital e a tecnologia ainda ausentes.

Como era de se esperar em um filme dedicado à representação da Amazônia como uma sociedade pronta para entrar na modernidade, uma porção extraordinária passa-se nos centros urbanos (um contraste dramático com o filme típico sobre a região). Porém, no trajeto de Iquitos a Manaus e até Belém (o qual é, implicitamente, o caminho para a modernidade), a filmagem incorpora vários trechos curtos retratando a vida no meio rural e insistindo na capacidade do homem do campo para se modernizar também. Podemos testemunhar um médico fazendo o percurso de pequenas aldeias na beira do rio em uma lancha, chegando a uma casinha modesta para administrar vacina a um menino bravo. A mensagem, claro, é que a Amazônia já provia de um sistema de bem-estar, possuindo uma preocupação moderna com a higiene e a saúde pública. Logo depois, fazemos uma visita a uma serraria, mais um indicador da potencial riqueza de uma região que contém, segundo o narrador, "inumerá- 
veis árvores silvestres ainda não tocadas". Aliás, durante o filme todo, repetidas vezes, o narrador nos lembra que os recursos naturais da Amazônia são inesgotáveis, e que a região oferece a qualquer pessoa com habilidade, capital e, sobretudo, tecnologia a possibilidade de explorá-los. Obviamente, este estoque infinito de recursos livra o empresário de qualquer preocupação com a questão da preservação ambiental.

A próxima escala será Manaus, normalmente apresentada nos anos 1940 como uma relíquia curiosa do ciclo da borracha, mera sombra do esplendor de outrora, no meio da floresta tropical. Mais uma vez, The Amazon awakens diverge das narrativas convencionais e, em oposição, representa Manaus como emblemática da modernidade incipiente, do despertar da Amazônia. E caso o público não estivesse suficientemente atento para captar essa mensagem, o "passeio" pela cidade era acompanhado pelo motivo musical de um trem em movimento, como a sincronizar a vida cotidiana de Manaus com os ritmos da modernidade industrial.

Longe de apresentar a imagem de uma cidade em declínio, na qual a floresta vai invadindo uma metrópole decadente, o filme nos mostra as forças tecnológicas afastando a floresta para criar mais espaço e acomodar uma urbe em expansão. Em cena particularmente apta para que se determine a época do filme, testemunhamos uma máquina escavadora utilizada na construção do aeroporto de Manaus esforçando-se por derrubar uma gigantesca árvore tropical que literalmente bloqueava o caminho do progresso. 0 cineasta aproveita o máximo desta cena, aumentando a tensão enquanto a árvore resiste à força da máquina; finalmente, a resistência revela-se inútil, e a árvore sucumbe (sob os aplausos silenciosos da platéia) ante o poder do homem e da tecnologia.

Igualmente obrigatório foi o segmento dedicado à contribuição brasileira, através do fornecimento de recursos estratégicos, à campanha da Guerra. 0 filme inclui uma cena dos "soldados da borracha" sendo despachados ao interior da floresta em meio à cerimônia normalmente associada à partida dos combatentes para a luta ${ }^{9}$. Aliás, soa um pouco irônico que esta cena traga a primeira referência à extração e ao comércio da borracha no filme; não houve antes nenhuma menção ao papel do ciclo da borracha na evolução dos centros urbanos nem no crescimento da população regional. Mesmo quando aborda Manaus, que deveu sua própria existência ao ciclo da borracha, a narração

9 Uma excelente discussão dessa campanha está em GARFIELD, Seth. Tapping masculinity: labor recruitment to the Brazilian Amazon during World War II. Hispanic American Historical Review, v. 86, n. 2, p. 275-308, May 2006. 
só se refere indiretamente ao tema, ao chamar alguns palacetes de produtos de "uma época de outrora" (mas a natureza dessa época não é especificada) ${ }^{10}$. Semelhante ao "desaparecimento" dos povos indígenas, este silêncio faz sentido dentro da óptica do filme. Afinal, num documentário sobre o "despertar" da Amazônia, seria altamente inconveniente lembrar ao público um outro momento histórico em que a Amazônia supostamente acordou, sendo que em seguida caiu novamente em sono profundo (pelo menos segundo as expectativas desenvolvimentistas). Por isso, ainda que seja responsável por boa parte do desenvolvimento urbano enaltecido no filme, o capítulo da história do ciclo da borracha precisa passar quase despercebido.

0 intervalo entre Manaus e Belém é o trecho mais comprido do filme que transcorre fora de um centro urbano. Primeiro, fazemos uma visita a um núcleo colonial onde o narrador nos informa, de novo, que "a floresta recua, cedendo a terra para esta comunidade modelo". Descendo o rio, chegamos ao ponto alto desse intervalo: uma visita a outro "reino mágico". Neste caso, não é a Disneylândia mas a Fordlândia, a experiência maciça de plantação de seringueiras iniciada por Henry Ford nos anos 1930. Apesar de já existirem bastantes provas do insucesso total dessa experiência, o retrato da Fordlândia no filme é inteiramente otimista e entusiasmado. Problemas como a incapacidade de superar as aflições botânicas e as dificuldades de impor disciplina industrial à mão-de-obra são deixados de lado, em favor de uma representação da Fordlândia que salienta seu valor em termos das “relações públicas”. Henry Ford vira o Príncipe Charmoso, o intrépido cavalheiro em campanha para trazer modernidade à floresta tropical. 0 filme também frisa os métodos científicos utilizados para enxertar as árvores, e a criação de um meio racional e higiênico para os trabalhadores. A Fordlândia é elogiada por providenciar "refeições cientificamente equilibradas para os futuros conquistadores da Amazônia”. E para encerrar esse segmento, o narrador declara ser a Fordlândia "um tributo ao talento e à ciência, as novas armas de um pioneiro do século XX."

$\mathrm{Na}$ verdade, o trecho demonstra melhor do que qualquer outro o compromisso dos cineastas com a Política da Boa Vizinhança: apresentar uma visão otimista do futuro da Amazônia e do papel dos Estados Unidos nesse futuro. Afinal, o filme fazia parte de uma imensa campanha de relações públicas, de uma

10 BURNS, E. Bradford. Manaus, 1910: portrait of a boom town. Journal of Inter-American Studies, v. 7, n. 3, p. 400-21, Aug. 1965; DAOU, Ana Maria. Instrumentos e sinais da civilização: origem, formação e consagração da elite amazonense. História Ciências Saúde-Manguinhos, Rio de Janeiro, v. 6, p. 867-888, set. 2000. Suplemento. 
produção da câmara do comércio numa escala sem precedentes. Uma conseqüência disso era a improbabilidade da equipe de Disney prestar atenção às pesquisas feitas em instituições como o Museu Goeldi, ou na própria Fordlândia, que já no início dos anos 40 indicavam que os solos amazônicos dificilmente poderiam sustentar a agricultura intensiva, ou que as pragas botânicas como a "ferrugem" das folhas nas seringueiras eram muito mais difíceis de resolver, um obstáculo muito mais sério ao cultivo da seringueira do que os cientistas imaginavam. Mas, além da necessidade de adotar um tom otimista por causa da Política da Boa Vizinhança, a exaltação da ciência e da tecnologia, tratadas como capazes de vencer qualquer obstáculo "natural", garantia que The Amazon awakens rejeitasse ou ignorasse qualquer conhecimento novo que questionasse a potencialidade da Amazônia para um certo padrão de desenvolvimento ${ }^{11}$.

É a respeito disto que o "texto visual" de Disney e o texto escrito de Hanson se distinguem da maneira mais dramática, e até se contradizem. Enquanto o documentário repete a velha noção da floresta tropical como uma região excepcionalmente rica e fértil, Hanson segue a linha mais atualizada; segundo ele, "os solos tropicais em geral ficam entre os solos menos férteis do mundo." ${ }^{2}$ É difícil imaginar que o staff de produção do filme não estivesse informado sobre isso. Mas esse tipo de "fato" perturbaria profundamente a linha narrativa do filme. A infertilidade do solo era também uma complicação para Hanson, mas ele podia alegar que variações no nível de fertilidade de uma subregião para outra indicariam que a colonização ainda poderia ser bem-sucedida se fosse implementada de modo organizado. Mais uma vez, com respeito ao filme e ao livro, o gênero e o contexto de produção distintos implicavam que os cineastas não podiam admitir certas "realidades" da situação da Amazônia, enquanto o geógrafo não podia ignorá-las.

Chegando a Belém do Pará, assistimos novamente a cenários que combinam o exótico e o bem-conhecido na cidade amazônica. É interessante notar que até o clima de Belém é vigorosamente elogiado - não somente a floresta tropical encerrava uma modernidade incipiente, mas ela não era tão tropical como as pessoas imaginavam (caso algum espectador continuasse acredi-

11 Para um retrato substancialmente menos retocado da Fordlândia, veja DEAN, Warren. Brazil and the struggle for rubber. Cambridge: Cambridge U. Press, 1987. cap. 5.

12 HANSON, Earl Parker. The Amazon: a new frontier. Nova Iorque: Foreign Policy Association, Mar. 1944. p. 45. 
tando na incompatibilidade entre clima tropical e construção da modernidade). E um pequeno detalhe: assistindo ao filme, uma pessoa poderia tranqüilamente concluir que nunca chovia no vale do Amazonas. Na Amazônia “imagineered" pelos Estúdios Disney, o tempo era sempre bom e os céus, sempre azuis ${ }^{13}$.

A cidade de Belém, como o principal porto do Baixo Amazonas, ilumina outro pressuposto do documentário. A filmagem prolongada dos barcos em descarga acentua a idéia de que os elementos materiais da modernidade provêm do exterior. Os nativos compartilham esta aspiração supostamente "universal" pelo progresso, e a região (especialmente nas cidades e na Fordlândia) já detinha os elementos essenciais da vida moderna. Contudo, uma plena modernização só poderia materializar-se através da venda dos recursos locais “super-abundantes” em troca de ciência, conhecimento e bens providenciados pelas economias mais avançadas.

0 passeio por Belém oferece também uma visita ao Instituto Agronômico do Norte, que, junto com o Museu Goeldi, era a entidade de pesquisa mais importante na Amazônia daquela época. Neste trecho, o cineasta não poupa esforços para acentuar e elogiar o empenho local no sentido de avançar a inovação técnica, mesmo a mais superficial, e o papel do instituto como auxiliar do processo de modernização. Há muita discussão, por exemplo, quanto a uma "experiência" absolutamente rotineira - o uso de um remo liso que produz "folhas" de seringa em vez das bolas mais tradicionais - "inovação" que pesquisadores paraenses haviam proposto décadas antes com o propósito de impedir a adulteração do látex pelos seringueiros que desejavam aumentar o peso do seu produto ${ }^{14}$. No filme esta "experiência" é apresentada como uma grande novidade; sem dúvida, Disney pretendia enaltecer o pessoal do Instituto, identificado como possíveis futuros colaboradores de pesquisadores do exterior, e, concomitantemente, demonstrar outra vez a existência de um “espírito de inovação" na Amazônia que estava acordando ${ }^{15}$.

13 A palavra "imagineered" significa, na linguagem especial do Estúdio Disney, a combinação de "imagined" (imaginado) and "engineering" (engenharia).

14 Sobre essa prática e outras formas de resistência e negociação por parte dos seringueiros, veja WEINSTEIN, Barbara. A borracha na Amazônia: expansão e decadência, 1850-1920. São Paulo: HUCITEC, EDUSP, 1993. cap. 6.

15 Sobre institutos de pesquisa na Amazônia durante essa época, veja MAIO, Marcos Chor; SÁ, Magali Romero. Ciência na periferia: a Unesco, a proposta de criação do Instituto Internacional da Hiléia Amazônica e as origens do Inpa. História Ciências Saúde-Manguinhos, Rio de Janeiro, v. 6, p. 975-1018, set. 2000. Suplemento. 
Para reforçar este último ponto, o segmento termina com o narrador asseverando que "o treinamento dos jovens nestes métodos científicos é de suma importância”.

A última seqüência do filme mistura filmagem ao vivo e desenho animado, criando um "sonho" do futuro, no qual a Amazônia está plenamente "acordada" e desfruta de um final feliz. A Bela, agora não Adormecida, é declarada um "paraíso de riqueza além dos sonhos humanos", e neste futuro projetado a região (aliás, toda a humanidade) vai aproveitar as riquezas produzidas por sua "terra rica, fértil e profunda". Um mapa aparece na tela com artérias estourando de toda parte da hiléia amazônica, projetando a futura exportação dessas riquezas a todos os cantos do mundo, e com desenhos em "technicolor" em que se imagina uma Amazônia cheia de edifícios ultramodernos e represas hidroelétricas gigantescas. Assim, a ciência e a tecnologia finalmente desencadeariam a realização dos antigos sonhos da Amazônia como "El Dorado".

0 filme The Amazon awakens nos oferece não somente um exemplo curioso e meio engraçado do modo como os cineastas norte-americanos envolvidos na Política da Boa Vizinhança representaram uma região tropical supostamente "atrasada" ou "subdesenvolvida". A sua narrativa também indica as origens e demonstra as tensões/contradições do que será chamado a "teoria da modernização" - uma teoria sociológica que dominará o conhecimento sobre a América Latina nas ciências sociais difundidas nos Estados Unidos no pós-guerra ${ }^{16}$. Embora seja geralmente presumido que esta teoria - com sua ênfase nos meios de comunicação, na alfabetização e na construção de novos valores e aspirações - originou-se nos corredores da academia e daí foi divulgada nos circuitos do poder, nossa análise do filme traz a possibilidade de o percurso ter sido exatamente inverso: uma agência do governo, num momento que exigia uma posição absolutamente "otimista" (e sem "racismos") com respeito ao futuro desenvolvimento da Amazônia (e da América Latina em geral), já estava articulando os argumentos "sine qua non" da teoria de modernização.

16 LATHAM, Michael E. Modernization as ideology: American social science and "Nation Building" in the Kennedy Era. Chapel Hill: University of North Carolina Press, 2000; GILMAN, Nils. Mandarins of the future: modernization theory in Cold War America. Baltimore: Johns Hopkins University Press, 2003. 
Começando nos anos 1940, os "missionários" da Política da Boa Vizinhança já esboçavam os pressupostos fundamentais do conceito de modernização. As premissas dessa teoria - os povos do Terceiro Mundo em geral (e da América Latina em particular) terem as mesmas aspirações e metas que os norte-americanos, existir um impulso universal e natural para o progresso, e só faltarem os meios suficientes para consolidar estes valores potencialmente "universais" (o conhecimento científico e técnico adequado e o capital de investimento) - já estavam expostas visualmente no filme The Amazon awakens. Além disso, os elementos da teoria são muito mais evidentes no filme de Disney do que no livro do geógrafo Earl Parker Hanson, com sua maior elaboração das questões da colonização e da raça. Talvez seja razoável atribuir as origens da teoria da modernização ao Office of the Coordinator of Inter-American Affairs de Nelson Rockefeller e aos Estúdios de Disney, em vez de aos cientistas sociais como Walt W. Rostow, Joseph Kahl, Daniel Lerner ou Alex Inkeles ${ }^{17}$. Afora essa questão concernente às origens, as ambivalências que marcam o filme (e ainda mais o livro de Hanson) aparecem na política norte-americana para com a América Latina durante os anos 1950 e 1960 e seriam, em geral, um aspecto mal resolvido da teoria da modernização. Os Estados Unidos, no auge da Política da Boa Vizinhança, acentuavam "semelhanças" (equivalências/igualdades), em vez de diferenças/alteridades, e caracterizavam a América Latina (mesmo a Amazônia!) como pronta e disposta a modernizar-se (isto é, como preparada para reproduzir a trajetória desenvolvimentista dos Estados Unidos e replicar a cultura da sua classe média). Entre outras coisas, isto significaria um processo acelerado de industrialização (e Hanson, inspirado nos livros do brasileiro José Jobim, falava com detalhes desse aspecto da modernização, inclusive da necessidade de criar novos impostos protecionistas no Brasil) ${ }^{18}$.

Ao mesmo tempo, o governo dos Estados Unidos não podia presenciar este processo inteiramente com bons olhos. Os interesses econômicos norte-americanos não estavam especialmente entusiasmados com a possibilidade de ver os países da América Latina mais industrializados, mais auto-suficientes (ou menos dependentes) ou, ainda pior, concorrendo com eles no mercado

17 ROSTOW, W.W. The economics of take-off into sustained growth. London: Macmillan, 1963; KAHL, Joseph. The measurement of modernism. Austin: University of Texas Press, 1968; LERNER, Daniel. The passing of traditional society. Glencoe, IL: The Free Press, 1958.

18 Hanson cita várias vezes o livro de JOBIM, José. Brazil in the making. Nova Iorque: Macmillan, 1943; ele o indica como "um excelente estudo do esforço atual brasileiro para a modernização.” 
mundial. Durante a guerra, as exigências das alianças resultaram em acordos como aquele que Getúlio assinou com Franklin Roosevelt para a construção de Volta Redonda, a primeira moderna fábrica de aço erigida na América Latina. Entretanto, a grande maioria dos políticos norte-americanos sempre conceberam esse processo como liderado pelos Estados Unidos, e pensavam nos países latino-americanos como parceiros de segundo grau que permaneceriam dentro de sua órbita econômica. Quando a II Guerra Mundial acabou, o governo Truman começou a pressionar os países latino-americanos a abrirem mão da política de industrialização ligada ao mercado interno e retomarem a ênfase na produção de mercadorias primárias e extrativas destinadas ao mercado mundial. (Voltarei adiante a este ponto) ${ }^{19}$.

É por isso que a Amazônia (em vez de São Paulo ou Antióquia, na Colômbia, regiões em pleno processo de industrialização) foi o tema perfeito para um filme produzido pelo Office of the Coordinator e por Disney. Além de oferecer os toques do pitoresco e do exótico, e da vantagem adicional no tocante à campanha da borracha, a Amazônia era um limiting case em dois sentidos. Por um lado, se seus habitantes, "adormecidos" por tanto tempo, podiam ser retratados como prontos e dispostos a receberem o beijo da modernidade, então certamente essa predisposição era extensiva a toda a América Latina. Por outro lado, "ninguém" (inclusive o governo brasileiro) acreditava que a Amazônia se tornaria uma nova Detroit ou Chicago. Apesar da interessante cena da industrialização em microcosmo no drama da fábrica de botões, no resto do filme eram os produtos "naturais" para exportação os recursos que a Amazônia poderia comerciar para adquirir a modernidade, quer na forma de conhecimento científico e tecnologia, quer na forma de bens de consumo. E a modernidade/modernização adquirida por este modo chegaria à Amazônia principalmente graças aos Estados Unidos. Em outras palavras, a imagem da Amazônia como um

19 As pressões oriundas dos Estados Unidos para os países latino-americanos reduzirem os impostos protecionistas e outras medidas em prol da industrialização são analisadas nos seguintes trabalhos: SMITH, Robert Freeman. United States policy-making for Latin America during the Truman administration. Continuity, v. 16, p. 87-111, Fall 1992; BETHELL, Leslie; ROXBOROUGH, Ian (Ed.). Latin American between the Second World War and the Cold War, 1944-1948. Cambridge: University Press, 1992; BETHELL, Leslie; ROXBOROUGH, Ian. Latin American between the Second World War and the Cold War: some reflections on the 1945-48 conjuncture. Journal of Latin American Studies, v. 20, n. 1, p. 167-89, May 1988; RABE, Stephen G. The Elusive Conference United States economic relations with Latin America, 1945-1952. Diplomatic History, v. 2, n. 3, p. 279-294, July 1978. Agradeço a Jason Guthrie, doutorando em História, da University of Maryland, pelas citações nesta nota. 
cofre tropical cheio de riquezas na forma de produtos naturais úteis para o mundo todo, e cuja abertura esperava apenas o emprego da nova tecnologia, permitia que os agentes da Política da Boa Vizinhança evitassem a questão um tanto complicada da industrialização e de seu papel no futuro da América Latina.

No entanto, essa orientação também exigia que pouca ou nenhuma referência fosse feita ao passado recente, especialmente ao ciclo da borracha (aquela época não especificada de outrora). Conquanto o filme se inicie com referências históricas, na verdade a Amazônia é representada ao longo dele como uma região à margem da história - afinal, o sono da Bela Adormecida é atemporal, fora do processo histórico. História só poderia "acontecer" uma vez que ela acordasse. Quanto ao ciclo da borracha, é claro que não se entrava nos detalhes dessa época de tristes conseqüências, especialmente porque o futuro econômico que os Estados Unidos imaginava para a Amazônia não contrastava radicalmente, à primeira vista, e apesar da atenção dedicada às virtudes das inovações tecnológicas, com aquele que havia sido prometido pelo ciclo da borracha. Afinal, a borracha é um produto natural, nativo da Amazônia, e fôra uma vez altamente procurado no mercado mundial, prometendo riquezas e progresso para a região. Seria impossivel esconder as semelhanças com os planos atuais e, por isso, era melhor nem mencionar aquele episódio do passado.

Já no caso de Earl Parker Hanson, que escreveu um trabalho semi-acadêmico, deixar de falar do ciclo da borracha não era uma opção. Em contraste com o filme, seu livro traz um capítulo com o título "Algumas lições da História”, boa parte do qual é dedicado às tristes lições do ciclo da borracha. Nele, Hanson logo encontra um problema previsível: como distinguir o ciclo da borracha, que constituiu uma economia que supostamente havia fracassado, chegando até (segundo ele) a retardar o desenvolvimento da região, da sua própria proposta econômica para o futuro da Amazônia? Para evitar confusão, Hanson cria o binômio "colonialismo x desenvolvimento verdadeiro" ${ }^{20}$. Segundo essa formulação, o ciclo da borracha era um exemplo de colonialismo porque nele a economia fora dominada por grandes empresas estrangeiras e organizada totalmente em termos de exportação e importação. Em oposição, sua proposta de colonização (que nunca poderia ser confundida com o colonialismo) previa propriedades de pequeno e médio porte, exploradas por

20 HANSON, Earl Parker. The Amazon: a new frontier. Nova Iorque: Foreign Policy Association, Mar. 1944. p. 43. 
colonos com hábitos modernos, produzindo uma diversidade de gêneros, dentre os quais até alguns de subsistência (para evitar a dependência excessiva em relação aos produtos importados). A proposta abriria, além disso, a possibilidade de criação de pequenas empresas industrializadas. 0 resultado (segundo Hanson): desenvolvimento verdadeiro.

Outro ponto de ambivalência, ou melhor dito, de ambigüidade nos trabalhos de Disney e de Hanson, este mais específico à Amazônia, era o lugar da "natureza" no caminho à modernização. De um lado, a natureza era a verdadeira fonte da riqueza que a Amazônia tinha a oferecer ao mundo; de outro lado, era também um obstáculo que o "Homem" precisava derrubar ${ }^{21}$. No filme, a saída do paradoxo foi pressupor uma infinidade de recursos brutos - os homens podiam cortar as árvores, desmatar as terras, expandir os núcleos coloniais, desenvolver a agricultura, e ainda o meio ambiente providenciaria um estoque inesgotável de borracha, madeira, babaçu, castanha, para fazer a Amazônia, e o mundo inteiro, mais prósperos. Em nenhum momento encontramos menção à idéia de conservação ou, como referido antes, à população indígena, que estava excluída da paisagem, ou mesmo a qualquer conhecimento que ela pudesse oferecer. A fé e o entusiasmo dos cineastas pelo valor da pesquisa científica e tecnológica não abrangiam as pesquisas que fornecessem resultados que contradissessem a sua visão "cor de rosa" da natureza e do futuro da Amazônia ${ }^{22}$. Este enorme otimismo com respeito ao poder transformador da tecnologia, do know-how americano, exigia uma rejeição de novos conhecimentos que pudessem sustentar um argumento divergente.

Há outros aspectos, não elaborados aqui, que merecem maior atenção. Por exemplo, se adotarmos a abordagem de gênero, vale notar que a Amazônia, no filme, está sempre posicionada como a fêmea - natural, passiva -, enquanto os Estados Unidos estão sempre colocados como o macho - racional, ativo. Dentro da lógica do filme, tanto quanto na lógica do desenvolvimentismo liberal, eles assumem os papéis da Bela Adormecida e do Príncipe Charmoso - e mesmo depois de ela receber o beijo

21 Para uma discussão de atitudes anteriores sobre a natureza na Amazônia, leia-se COELHO, Geraldo Mártires. Êxtase e estranhamento em A Selva, de Ferreira de Castro. In: FORTUNA, Carlos; LESSA, Renato (Org.). Travessia. Rio de Janeiro: Iuperj, 2001. v. 1, p. 23-61.

22 Warren Dean analisa as tentativas dos institutos regionais de conciliarem um impulso para o desenvolvimento com os resultados desanimadores das pesquisas agronômicas. DEAN, Warren. Brazil and the struggle for rubber. Cambridge: Cambridge U. Press, 1987. cap. 7. 
do príncipe, este certamente vai acompanhá-la e orientá-la no caminho da modernidade.

$\mathrm{Na}$ primeira parte deste artigo, frisei as diferenças entre The Amazon awakens e qualquer filme norte-americano sobre a Amazônia lançado nos últimos trinta anos. Mas enquanto as descontinuidades são dramáticas e óbvias, há uma continuidade que vale a pena destacar: a tendência a tratar a Amazônia como uma fonte de recursos internacional ou ainda mundial. Tanto o filme de Disney quanto o livro de Hanson chamam a Amazônia de "fronteira para a humanidade". No filme, partindo da primeira seqüência, o futuro da região é apresentado como uma preocupação não apenas para as "Seis Grandes Nações" que dividem seu território, mas para todas as nações do mundo (e a linguagem do filme deixa claro que esse interesse global persistiria além da campanha da Segunda Guerra Mundial). Em contraste com os territórios do Oeste dos Estados Unidos, que eram fronteira para o "destino manifesto" especificamente dos (norte) americanos, é significativo que a Amazônia seja colocada como uma fronteira para a "humanidade". Essa visão da Amazônia como uma região de importância transnacional, cujo destino é uma questão para a humanidade toda, ainda está presente no discurso dos atuais movimentos ambientalistas baseados nos Estados Unidos; aliás, este segue como elemento duradouro e contínuo de quase todas as representações norte-americanas da Amazônia. A construção da Amazônia como uma região cuja importância a coloca fora das definições e normas da soberania nacional talvez sirva, por sua vez, para perpetuar as ansiedades brasileiras, às vezes exageradas, às vezes não, para com a chamada "cobiça internacional"23.

Para terminar, quero retomar o tema da teoria de modernização e tratar um pouco de uma expressão presente no título de meu artigo, mas que ainda não apareceu no texto: a "Guerra Fria”. É óbvio que os dois textos - o filme de Disney e o livro de Hanson - são muito influenciados pelo momento histórico de sua criação, que era o de um estado de guerra "mundial" e da aliança excepcional entre os Estados Unidos e a União Soviética. Porém, tanto um quanto outro projetaram suas visões para além do futuro próximo e insistiram em que estas novas tendências

23 A expressão é de REIS, Arthur Cézar Ferreira. A Amazônia e a cobiça internacional. Rio de Janeiro: Editora Americana, 1972. (1º edição de 1960). 
continuariam e até se acelerariam depois da guerra. Hanson falou explicitamente disso, ao escrever o seguinte:

[...] Parece razoável esperar que a Política da Boa Vizinhança seja uma realidade depois da guerra. Há pouca possibilidade de que nossa política se altere no pós-guerra de uma maneira que impedirá o desenvolvimento da Amazônia ou nos levará a negar à América Latina os elementos de produção que seriam essenciais para um processo generalizado de industrialização nacional. ${ }^{24}$

Hanson não estava totalmente errado; alguns programas e projetos orientados a apoiar a industrialização na América Latina sobreviveram no pós-guerra ${ }^{25}$. Mas, de modo geral, nesse período a política econômica norte-americana estava voltada à Europa, à grande preocupação de recuperar a economia da Europa ocidental e central. Correlacionado a isso, a América Latina regressou ao papel de consumidora de bens fabricados na Europa e nos Estados Unidos e de fornecedora de produtos brutos. Como lamentou o político e empresário Roberto Simonsen, não havia um "Plano Marshall” para a América Latina.

Quanto à teoria da modernização, surgiu, no primeiro instante, da Política da Boa Vizinhança durante a guerra. Porém, como uma receita para a modernização e o desenvolvimento, só floresceu no fim dos anos 1950 e início dos anos 1960. Como podemos explicar esse longo intervalo entre suas primeiras manifestações e sua divulgação como principal suporte ideológico da política norte-americana na América Latina? Para responder à pergunta, temos de voltar nossa atenção brevemente ao advento da Guerra Fria e à adoção pelo governo norte-americano da estratégia de "containment" - de não permitir a expansão do comunismo além das fronteiras do Bloco Soviético. Conforme já indiquei, isto significava, em primeiro lugar, investir o capital e os recursos tecnológicos disponíveis na reconstrução da Europa, como linha de frente contra a "ameaça vermelha".

E a América Latina, a Boa Vizinha que apoiou os Estados Unidos durante a guerra toda? Teoricamente, a Política da Boa Vizinhança continuava sendo a posição oficial dos Estados Unidos com respeito à região. Contudo, na prática, o "realismo"

24 HANSON, Earl Parker. The Amazon: a new frontier. Nova Iorque: Foreign Policy Association, Mar. 1944. p. 86.

25 Veja, por exemplo, ESTADOS UNIDOS. Joint Brazil-United States Economic Development Commission. Brazilian Technical Studies. Washington, DC: Government Printing Office, 1954. 
de George Kennan, arquiteto da estratégia de containment, tornou-se a política dominante para a América Latina no pósguerra. Isto não só significava uma transformação nas práticas diplomáticas e nos projetos econômicos, mas na própria visão da América Latina. Não há melhor exemplo desta "nova" orientação do que um relatório de autoria do próprio Kennan, feito no início de 1950 a pedido do Secretário do Estado, Dean Acheson ${ }^{26}$. Para escrever esse relatório, Kennan fez sua primeira e única visita à América Latina; no documento (que era, na época, "secreto"), ofereceu seus pensamentos e suas impressões sobre a região e seu papel na luta contra o comunismo.

0 relatório começa com uma avaliação do valor estratégico da América Latina. Para Kennan há apenas dois motivos para manter boas relações com a região: primeiro, "podemos eventualmente depender deles para recursos essenciais à execução de guerra"; segundo, o povo latino-americano "pode influenciar a tendência política geral na comunidade internacional". Até agora é possível imaginar que ele vá recomendar algo pouco diferente da Política da Boa Vizinhança. Mas no parágrafo seguinte (há que se levar em conta que o documento era "secreto") o tom deixa claro que ele está muito longe de sugerir algo do gênero. Ele introduz esta nova parte do relatório com a ponderação que citamos abaixo:

Parece-me improvável que exista outra região na face da Terra na qual a natureza e o comportamento humano possam ter-se combinado para produzir um contexto mais infeliz e mais deprimente para a conduta da vida humana do que na América Latina.

Os parágrafos subseqüentes são um espetáculo de hispanofobia e racismo. Kennan recupera a Lenda Negra e condena o despotismo e a crueldade dos conquistadores ibéricos, bem como seu sangrento e brutal tratamento dos índios (estes últimos tendo sido aparentemente super-bem tratados nas colônias anglo-saxônicas). Caso alguém pense que isso indica uma simpatia pelos povos não brancos, ele prossegue assim:

Em outras partes da América Latina [talvez o Brasil?], a importação em larga escala dos escravos negros... e a mestiçagem extensiva de todos estes elementos produziram outros resultados

26 ESTADOS UNIDOS. Department of State. Memorandum by the Counselor (Kennan) of the Department to the Secretary of State, 29 Mar. 1950. The United Nations, The Western Hemisphere. Washington, DC: Government Printing Office, 1976. p. 598-624. (Foreign Relations of the United States, 1950, v. 2). 
muito infelizes, que pesam da mesma maneira na potencialidade para o progresso humano. Nessas circunstâncias, a sombra de uma tremenda impotência e inutilidade cai hoje pela maior parte do mundo latinoamericano. Os impedimentos ao progresso são inscritos com sangue humano...

Obviamente, de um povo tão fraco, retrógrado e defeituoso, seria difícil esperar uma democracia suficientemente forte e estável para repelir o comunismo, e muito menos um processo bem-sucedido de modernização. Então, qual é a recomendação de Kennan?

Temos que conceder que duras e severas medidas governamentais de repressão seriam a única solução; e é possível que estas medidas provenham de regimes cujas origens e métodos não seriam aprovados no contexto norte-americano. ${ }^{27}$

Quanto aos interesses econômicos norte-americanos, Kennan parte da premissa de que este tipo de regime "naturalmente" favoreceria esses interesses, e de que, se uma empresa estrangeira encontrasse alguma dificuldade, poderia valer-se (judiciosamente) do suborno (pelo menos, é o que ele recomenda). Enfim, no "filme" de Kennan, a América Latina vira uma personagem de terceira categoria, sem nenhum potencial para tornar-se estrela.

Não quero prolongar demais a conclusão deste artigo. Penso que é bastante evidente que, enquanto a Política da Boa Vizinhança se alicerçava numa noção universal do ser humano e era um discurso que acentuava as semelhanças culturais entre os norte-americanos e os latino-americanos, a política realista voltava ao discurso da "diferença", da alteridade, da superioridade e da inferioridade, deixando de lado qualquer questão relativa à modernização, menos no sentido mais superficial. Claro que a visão liberal/universal do mundo, e do futuro, tinha seus próprios defeitos. Esta visão se baseava num conceito normativo e homogeneizado da cultura, promovendo uma noção de desenvolvimento-padrão que não correspondia às realidades e dificuldades enfrentadas pelas sociedades pós-coloniais e ignorando a persistência de padrões de hegemonia e hierarquia na economia global, que serviam como impedimentos a qualquer

27 ESTADOS UNIDOS. Department of State. Memorandum by the Counselor (Kennan) of the Department to the Secretary of State, 29 Mar. 1950. The United Nations, The Western Hemisphere. Washington, DC: Government Printing Office, 1976. p. 598-624. (Foreign Relations of the United States, 1950, v. 2). 
tentativa de transformação econômica. Esses problemas e contradições já apareciam no trabalho de Hanson, com sua tentativa de imaginar um Brasil moderno e industrial em que o colono branco (e supostamente não-brasileiro) era a única figura capaz de garantir a modernização da hiléia amazônica.

Seria fácil concluir que Hanson era um simples racista, idêntico a Kennan. E de certa forma, ele era. Mas havia uma diferença significativa entre os dois. É provável que Kennan imaginasse uma América Latina onde a única opção era uma estrutura sócio-econômica na qual um pequeno grupo de brancos continuava dominando uma população semi-colonial e incapaz de participar plenamente da vida moderna do "Primeiro Mundo". Para Hanson, o sujeito moderno era o homem (branco) da classe média, aquele que avançava pelos seus próprios esforços em vez de pela exploração dos outros, servindo como modelo a ser seguido e imitado pelos povos menos modernos (e menos brancos). Ou, segundo o filme de Disney, fornecendo o capital e a tecnologia que ainda faltavam para esses povos "acordarem" e modernizarem-se plenamente.

0 relatório de Kennan, mesmo com seu racismo e hipérboles, não era um documento trivial ou idiossincrático. Pelo contrário, ele captou bem o "clima" da política norte-americana com relação à América Latina naquela primeira fase da Guerra Fria. Aliás, poucos anos depois, na Guatemala, a CIA fez exatamente o que ele recomendava: organizou uma invasão e o golpe contra o governo modernizador de Jacobo Arbenz e instalou um regime autoritário e repressivo.

Somente no fim da década de 1950, depois da reação furiosa contra a intervenção na Guatemala, da recepção violenta do Vice-Presidente Nixon em 1958, e, claro, da Revolução Cubana no ano seguinte, o governo norte-americano comprometeu-se com uma política hemisférica definida pela teoria da modernização e escorada nos conceitos anteriormente visualizados em The Amazon awakens. 0 resultado foi a Aliança para o Progresso, cuja trajetória nada tinha a ver com um conto de fadas e que tampouco possuía um final feliz, mas esta é outra história. 